\title{
Evaluating Negative Attributions in Persons with Brain Injury: \\ A Comparison of Two Measures
}

\author{
Dawn Neumann, PhD (corresponding author) \\ Associate Professor, Indiana University School of Medicine, Department of Physical Medicine \\ and Rehabilitation, Indianapolis, IN \\ Research Director, Rehabilitation Hospital of Indiana \\ Angelle M. Sander, $\mathrm{PhD}$ \\ Associate Professor and Director, Division of Clinical Neuropsychology and Rehabiltiation \\ Psychology \\ Baylor College of Medicine and Harris Health System, Department of Physical Medicine and \\ Rehabilitation, Houston, TX \\ Senior Scientist and Director of the Brain Injury Research Center, TIRR Memorial Hermann \\ Noelle Witwer, BA \\ Medical Student, Indiana University School of Medicine, Indianapolis, IN \\ Jeong Hoon Jang, $\mathrm{PhD}$ \\ Assistant Professor, Indiana University School of Medicine, Biostatistics Department, \\ Indianapolis, IN \\ Surya Sruthi Bhamidipalli, MPH \\ Biostatistician, Indiana University School of Medicine, Biostatistics Department, \\ Indianapolis, IN \\ Flora M Hammond, MD \\ Nila Covalt Professor and Chair, Physical Medicine and Rehabilitation, \\ Indiana University School of Medicine, Indianapolis, IN \\ Chief of Medical Affairs, Rehabilitation Hospital of Indiana
}

Conflicts of Interest and Source of Funding: None

This study was funded by the National Institute on Disability, Independent Living, and Rehabilitation Research (NIDILRR), award \# 90IF00-95-01-00.

This is the author's manuscript of the article published in final edited form as:

Neumann, D., Sander, A. M., Witwer, N., Jang, J. H., Bhamidipalli, S. S., \& Hammond, F. M. (2021). Evaluating Negative Attributions in Persons With Brain Injury: A Comparison of 2 Measures. The Journal of Head Trauma Rehabilitation, 36(3), E170-E177. https://doi.org/10.1097/HTR.0000000000000635 


\section{ABSTRACT}

Objectives: Compare two negative attribution measures for construct and predictive validity in participants with traumatic brain injury (TBI). Readability and time-to-administer were also compared.

Setting: Two traumatic brain injury rehabilitation hospitals.

Participants: Eighty-five adults with TBI.

Design: Comparison of measures.

Main Measures: Negative attributions (intent, hostility, and blame) and anger responses to hypothetical scenarios were measured with the Epps Scenarios and the Ambiguous Intentions Hostility Questionnaire (AIHQ). Trait aggression was measured with the Buss-Perry Aggression Questionnaire (BPAQ).

Results: Associations between attributions and anger responses (i.e., construct validity) within each measure were significant (Epps: $\mathrm{r}=.61-.74$; AIHQ: $\mathrm{r}=.39-.71$ ); however, associations were stronger for Epps (p’s <.001). Receiver-operating characteristics revealed attributions from both measures were able to predict BPAQ scores (AUC's 0.6-0.8); predictive validity did not statistically differ between the two measures. Both had comparable readability $\left(5^{\text {th }}-6^{\text {th }}\right.$ grade level), but Epps had longer administration times.

Conclusion: Negative attributions impact anger and aggression after TBI, therefore making it important to identify suitable assessments for the TBI population. While psychometric properties of the Epps and AIHQ should be further explored, this study offers early support for the use of either instrument in persons with TBI. Advantages and disadvantages of the Epps and AIHQ are highlighted.

Key Words: intent, hostility, blame, attributions, anger, brain injury. 
Chronic problems with anger and aggression are typical after a traumatic brain injury (TBI). ${ }^{1}$ A series of recent studies in the TBI population indicate that anger in response to specific events is related to how they judge others' actions., ${ }^{2,3}$ The more intentional, hostile, and blameworthy they judged others' actions, the stronger their self-reported anger. Research further found that participants with TBI judged others' actions more negatively than their uninjured counterparts. ${ }^{3}$ The relationship between these types of judgements (i.e., intent, hostility, and blame) and anger is known as the attribution-emotion association ${ }^{4-6}$, and the tendency to disproportionately judge others' actions as negative or more extreme than the norm is referred to as negative attribution bias. ${ }^{5,7,8}$ In addition to the anger associations, negative attributions have been associated with higher aggression in samples with and without TBI. ${ }^{5,7-10}$ Together, these discoveries are an important advancement towards understanding mechanisms related to postTBI anger and aggression.

There is a clear need for identifying good measures for assessing negative attributions in the TBI population. To-date, only two measures that have been used in TBI research to evaluate negative attributions: $:^{2,3,11,12}$ Epps Scenarios ${ }^{5}$ and the Ambiguous Intentions Hostility Questionnaire (AIHQ). ${ }^{8}$ The Epps Scenarios was originally created and tested in a college sample..$^{5}$ The AIHQ was created for people with schizophrenia ${ }^{6}$ and has been the recommended measure for assessing negative attributions in the schizophrenia population. ${ }^{13}$ Both measures consist of written scenarios describing situations where characters' actions hypothetically result in an undesirable outcome for the reader. Scenarios either describe the character's behavior as benign, hostile, or ambiguous. Participants' self-reported anger responses and their attributions about the characters' behaviors are collected for each scenario. Because biases are expected to play a pronounced role in shaping interpretations of unclear actions (versus actions with clear 
intent), ambiguous scenarios are often the primary focus ${ }^{8,13}$ Consistent with this expectation, our former research using the AIHQ found effect sizes to be the largest for the ambiguous scenarios when comparing participants with and without TBI. ${ }^{11}$

When it comes to the selection and adoption of assessments for research and clinical use, psychometric properties and the practicality of the instrument are important factors. Initial support for the use of the Epps Scenarios ${ }^{3}$ and $\mathrm{AIHQ}^{11,12}$ in the TBI population comes from past results indicating that they are both capable of detecting differences in negative attributions between participants with and without TBI. These past studies also suggested acceptable construct validity, as indicated by moderate to strong attribution-anger associations. ${ }^{3,11,12}$ However, it is currently unclear how the Epps and AIHQ compare to one another. Additionally, practicality factors have not been systematically examined. More information about how these measures compare to one another may help clinicians and researchers decide which instrument to use for evaluating post-TBI attributions, based on their setting and needs. The overarching objective of the current study is to examine and compare strengths and limitations of the Epps Scenarios and AIHQ with regards to some basic validity properties and practicality. $\underline{\text { Specific }}$ aims were: 1) To compare construct validity between Epps and AIHQ negative attribution measures (i.e. strength of relationships between negative attributions and anger response); 2) To determine and compare the predictive validity of Epps and AIHQ for predicting trait aggression; 3) To determine negative attribution cut-off scores for the AIHQ and Epps with regard to classification of subjects who have aggression traits that are higher than the average range on a standard aggression measure; and 4) Compare readability statistics and administration time between the AIHQ and Epps scenarios.

\section{METHODS}




\section{Participants}

The current study included 85 participants with complicated mild to severe TBI, which was a subsample of a larger study on negative attributions $(n=210,105$ TBI and 105 peer controls) that was conducted at two rehabilitation centers in Indiana and Texas.(in press) The AIHQ was an optional assessment at the end of the study visit. Only participants with TBI who completed both the AIHQ and Epps measures were included in the current sample. The 85 participants with TBI who opted to complete the AIHQ did not differ in age, sex, education, years post-injury, injury etiology, or injury severity from the 20 participants who opted not to complete the AIHQ for ( $\mathrm{p}>.05)$. Both sites received ethics review board approval. Participants were recruited via letters from physicians or patient registries, support groups, and newsletters. The sample included adult ( $\geq 18$ years old) who incurred a TBI at least six months prior who also met the following injury severity criteria: Glasgow Coma Score $<13$, post-traumatic amnesia $\geq 24$ hours, loss of consciousness $\geq 30$ minutes, or CT scan showing intracranial abnormality. Participants reported no other neurological disorder, history of major psychiatric disorder, or developmental disability. All participants spoke fluent English, and demonstrated adequate comprehension on either a short written or orally presented narrative (determined by Discourse Comprehension Test) ${ }^{2}$. Sample demographics and injury data are provided in Table 1.

<Insert Table 1 here $>$

\section{Measures}

Ambiguous Intentions Hostility Questionnaire (AIHQ): ${ }^{8}$ The AIHQ, comprised of 15 written scenarios that describe characters' behaviors as intentional, ambiguous, or accidental (5 scenarios per category), were read aloud to participants. Participants rate their perceived intent and blame, as well as their own anger response to the character's actions on a Likert scale. The 
Likert scale for Intent is a 6-point scale, whereas Blame and Anger use a 5-point Likert scale. The AIHQ also includes 2 open-ended questions to capture perceived hostility (i.e., what do you think the real reason was for the character's actions?), and hypothetically aggressive responses (i.e., What would you do about it?). Two independent raters scored participants' responses on a Likert scale for degree of perceived hostility $(1=$ not hostile/accidental to $5=$ very hostile/intentional) and how aggressive their anticipated behavioral response was $(1=$ not aggressive to $5=$ Very aggressive). ICC's ranged from good to excellent for both (.60-1.00), ${ }^{11}$ therefore the ratings from the two raters were averaged. Aggressive responses are not reported here as there is not a comparable item on the Epps. Psychometric testing in other populations indicates adequate reliability and validity. ${ }^{8,13-15}$ The AIHQ scores for intent, hostility, blame attribution and anger response were created by averaging the corresponding Likert-scale ratings across 5 ambiguous scenarios and across all 15 scenarios (intentional, ambiguous and accidental combined). See Supplemental Digital Content for an example AIHQ item and scoring. Epps' Hypothetical Scenarios: Attribution and Anger Ratings. ${ }^{5}$ This measure includes 21 written scenarios that describe characters' actions that are benign, ambiguous, or hostile (7 scenarios per category). The written narratives were always visibly displayed on a computer screen. Pre-recorded narrations of the Epps' scenarios were played in conjunction with the written text displayed on the computer screen for participants who demonstrated better auditory comprehension (versus written comprehension) on their DCT screening assessment. The narrated recordings were created in a neutral tone of voice. Participants rated each scenario on a 9-point Likert scale for how intentional, hostile, or blameworthy they perceive the character, and rated their anticipated anger in response to the scenario. The Epps scores for intent, hostility, blame attribution and anger response were created by averaging the corresponding Likert-scale ratings 
across 5 ambiguous scenarios and across all 15 scenarios (benign, ambiguous and hostile combined). This measure has been reported to have good construct and predictive validity in a college sample, ${ }^{5}$ and acceptable contruct validity in a TBI sample. ${ }^{3}$ See Supplemental Digital Content for an example of the Epps Scenarios.

Buss-Perry Aggression Questionnaire (AQ). ${ }^{16}$ This instrument measures overall aggression through items that assess for physical and verbal aggression, anger, and hostility. Participants are presented thirty-four statements and asked to rate each on a 5-point scale for the extent to which it is characteristic of them self. Total $\mathrm{T}$ scores derived from age and gender norms were used for analyses. The AQ is a psychometrically sound and widely used measure ${ }^{16}$, including use in TBI populations. ${ }^{17-21}$

\section{DATA ANALYSES}

To evaluate the construct validity of the AIHQ and Epps measures, Spearman's rank correlation coefficients $\left(\hat{\rho}_{s}\right)$ were computed to estimate the degree of association between each of the attribution scores (intent, hostility and blame) and anger score for ambiguous-only scenarios and all scenarios combined, separately for each measure, and interpreted as very weak $(0.00-0.19)$, weak $(0.20-0.39)$, moderate $(0.40-0.59)$, strong $(0.60-0.79)$, very strong $(0.80$ $-1.00) .{ }^{22}$ To compare construct validity between the AIHQ and Epps, a test for two dependent correlations ${ }^{23}$ was used to compare their Spearman's rank correlations (attribution-anger associations).

The predictive validity of the AIHQ and Epps (i.e., the ability of intent, hostility and blame scale scores from each measure to predict higher-than-average aggression trait on a BussPerry AQ (total score $\geq 56$ ) was assessed using receiver-operating characteristics (ROC) ${ }^{24}$ analysis. ROC curve plots sensitivity against 1-specificity across the range of all possible cutoff 
points and the area under the ROC curve (AUC) summarizes the overall predictive accuracy. In general, AUC of 0.5 is considered a worthless test, $0.5-0.6 \mathrm{bad}, 0.6-0.7$ sufficient, $0.7-0.8$ good, $0.8-0.9$ very good, and greater than 0.9 considered excellent. ${ }^{25}$ AUCs were also used to evaluate the predictive accuracy of AIHQ and Epps composite scores that combine the average scores for respective intent, hostility and blame scales as a weighted linear combination (composite_score $=b_{0}+b_{1} *$ intent_score $+b_{2} *$ hostility_score $+b_{3} *$ blame_score), where weights $\left(b_{0}, b_{1}, b_{2}\right.$ and $\left.b_{3}\right)$ are obtained by fitting a logistic regression that regresses the binary aggression outcome (Buss-Perry AQ total score $\geq 56$ or $<56$ ) on intent, hostility and blame scores. Predictive validity of AIHQ and Epps was compared using a nonparametric statistical test that can compare their $\mathrm{AUCs}{ }^{26}$ within each attribution (e.g., AIHQ intent vs. Epps intent, AIHQ composite vs. Epps composite). An optimal cutoff point that maximizes the Youden's J index ${ }^{27}$ (sensitivity + specificity -1) was derived for each of the AIHQ and Epps attributions and composite scores to aid in future classification of subjects into either higher-than-average or lower-than-average aggression trait on a Buss-Perry AQ (total score $\geq 56$ and $<56$, respectively). Tests were two-sided with significance level of 0.05 . SAS software version 9.4 (SAS Institute Inc, Cary, NC) was used to conduct analyses.

Test administration times were calculated from 10 randomly selected subjects. The Readability Statistics function in Microsoft Word was used to determine the following for each item (scenario): total words, words per sentence, sentences per paragraph, Flesch Reading Ease score $(100-90=$ very easy; $90-80=$ easy; $80-70=$ fairly easy; $70-60=$ understood by $13-15$ year olds; 60-50=fairly difficult; 50-30=difficult; 30-0=very difficult), and Flesch-Kincaid Grade Level. Total average Readability Scores were calculated for each measure.

\section{RESULTS:}




\section{AIHQ and Epps Construct validity}

Construct validity details for both measures are provided in Table 2. For AIHQ, the intent attribution was moderately correlated with the anger response, regardless if the attribution and emotion scores were calculated from all scenarios (ambiguous, intentional and accidental) combined (Spearman's rank correlation $\left[\hat{\rho}_{S}\right]=0.50 ; 95 \%$ confidence interval $[\mathrm{CI}]: 0.33-0.65$ ) or from ambiguous scenarios only $\left(\hat{\rho}_{s}=0.57 ; 95 \% \mathrm{CI}: 0.41-0.70\right)$. A weak correlation was identified between the hostility attribution and anger response under all scenarios combined $\left(\hat{\rho}_{s}=\right.$ 0.39; $95 \%$ CI: $0.19-0.55)$, whereas a moderate association was found under only the ambiguous scenarios $\left(\hat{\rho}_{s}=0.49 ; 95 \%\right.$ CI: $\left.0.30-0.63\right)$. For blame attribution, scores were significantly strongly correlated with anger responses that were calculated from all scenarios $\left(\hat{\rho}_{s}=0.65 ; 95 \%\right.$ CI: $0.50-0.76)$ and from only ambiguous scenarios $\left(\hat{\rho}_{s}=0.71 ; 95 \% \mathrm{CI}: 0.59-0.80\right)$. For Epps, attributions of intent, hostility and blame were all strongly correlated with the anger responses under all scenarios (benign, ambiguous and hostile) combined and under ambiguous-only scenarios (all $\hat{\rho}_{s}$ between 0.60 and 0.79 ). The degrees of association (correlations) between Epps negative attributions and Epps anger response were significantly stronger than those between AIHQ negative attributions and AIHQ anger response under all configurations (all p-values < $0.001)$.

\section{$<$ Insert Table 2 here $>$}

\section{Predictive Validity of AIHQ and Epps Negative Attributions}

All individual AIHQ intent, hostility and blame score scales had sufficient predictive validity (all AUCs between 0.6 and 0.7 ) in identifying participants with TBI who had higherthan-average trait aggression (Buss-Perry AQ total score $\geq 56$ ). Likewise, AIHQ composite 
scores, which were formed as weighted linear combinations of the three AIHQ negative attributions (see footnote of Table 3 for data-driven weights), exhibited sufficient predictive validity under both ambiguous ( $\mathrm{AUC}=0.638 ; 95 \% \mathrm{CI}: 0.519-0.757)$ and all scenarios (AUC $=0.686 ; 95 \%$ CI: $0.570-0.802$ ). All individual Epps intent, hostility and blame scores, as well as Epps composite scores (see footnote of Table 3), had good predictive validity with AUCs in the $0.7-0.8$ range (except for Epps blame under ambiguous scenarios). As for the comparison of predictive validity between the two measures, the AIHQ and Epps did not statistically differ; however, trends indicated Epps intent (all scenarios) and ambiguous-only Epps hostility and composite scores had marginally higher AUCs than those of the corresponding AIHQ scores (Pvalues $=0.093,0.065$ and 0.081 , respectively). Table 3 summarizes the optimal cutoff points of AIHQ intent, hostility, blame and composite scores for detecting higher-than-average aggression trait, and respective sensitivity and specificity.

\section{$<$ Insert Table 3 here $>$}

\section{Administration Time and Readability Statistics}

Table 4 provides descriptive statistics for administration time and readability of the items within AIHQ and Epps. Median scores indicated Epps took almost 12 minutes longer to administer than AIHQ. Median outcomes from the readability statistics deemed the AIHQ as "easy" to read (87.4 reading ease) and classified it at a $5^{\text {th }}$ grade reading level. Median scores indicated the Epps was "fairly easy" to read (77.2 reading ease ) and ranked it at a $6^{\text {th }}$ grade reading level. The AIHQ had an item that reached a $10^{\text {th }}$ grade reading grade level, whereas all Epps items were below $9^{\text {th }}$ grade. 


\section{DISCUSSION}

Skewed perceptions of intent, hostility, and blame are relevant to problems with anger and aggression, and compared to the general population, persons with TBI appear to be at greater risk for negatively judging others' behaviors. ${ }^{3}$ Negative attributions are typically not assessed in TBI, despite the potential role in understanding and treating anger and aggression. This gap requires proper assessment tools. Towards the goal of identifying instruments to assess negative attributions in the TBI population, this study evaluated some fundamental properties of the AIHQ and Epps measures.

The first aim of the study was to examine and compare construct validity (attributionanger associations) of the AIHQ and Epps assessments. Because ambiguous scenarios are believed to be the crux of negative attribution bias, results were examined for the full measures (all scenario types: ambiguous, benign, and hostile scenarios), as well as for ambiguous-only items. Findings support the construct validity of both the AIHQ and the Epps measures, with results showing that attributions of intent, hostility, and blame were significantly and positively correlated with anger responses to the scenarios. Comparatively, construct validity was significantly stronger for the Epps than the AIHQ. For the Epps measure, all attribution-anger associations were strong. In contrast, AIHQ attribution relations with anger varied. Findings indicated moderate associations for intent, yet strong associations for blame (all scenarios and ambiguous-only); and hostility attribution relations were found to be weak when all scenarios were used, but moderate when based on ambiguous-only scenarios. It was interesting to find the hostility-anger associations in the AIHQ to be the weakest (.39 and .49 , respectively). This may be the biproduct of an open-ended question which required a rater from the research team to score the subjects' responses. This might be a limitation of the AIHQ, especially if hostile attributions are a key focus. If standardized scoring for these open-ended questions was 
available, it might strengthen these relationships. However, our raters underwent rigorous training by the AIHQ author. Alternatively, it has been suggested that validity properties of the AIHQ might be further enhanced if there were self-rated items (as opposed to open-ended). ${ }^{14}$

Another aim was to explore how well AIHQ and Epps attribution scores reflect aggressive traits. The AIHQ had "sufficient" predictive validity for trait aggression based on composite attribution scores (average intent+average hostility+average blame), as well as from individual attribution scores, regardless if ambiguous-only scenarios or the full set of scenarios. Predictive validity of attributions from the Epps was "good" for all (composite and individual attributions), except when blame attributions were derived from ambiguous-only scenarios, which were classified as sufficient. Although the Epps achieved higher nominal classification accuracy (good versus sufficient) for the most part, the predictive accuracy between the two measures did not statistically differ. These findings might have differed with a larger sample size, especially for Epps attributions that were trending towards significance.

Another aim was to identify specific cut-off scores that can help to differentiate those with higher than average aggression. While these numbers are still preliminary and should be treated with caution, it is a starting point to assist researchers and clinicians with identifying participants who might be at risk for having aggression problems. Sensitivity values indicated the Epps cut-off scores would be generally more accurate at detecting someone who truly had trait aggression (69-92\% probability), than would the AIHQ (50-71\%). For the Epps, Composite scores (full measure) and Blame (ambiguous only) had the highest sensitivity in detecting trait aggression. The AIHQ had greater specificity than it did sensitivity, meaning it would more likely to accurately classify someone as not aggressive who truly did not have high aggressive traits (62-81\%). In contrast, the Epps had lower specificity than it did sensitivity (43\%-76\%). 
In terms of practicality and readability of the two measures, the standout factor was administration time for the Epps. Median data suggested it usually took about 30 minutes to administer the full measure (approximately 12 minutes longer than the AIHQ). Although the reading ease is slightly lower for the Epps, it is still considered "fairly easy" and is mostly at a $6^{\text {th }}$ grade reading level. That said, there are more sentences per item in the Epps than the AIHQ measure, meaning more reliance on working memory when answering questions about that scenario. This might be more challenging for some participants with TBI and is worth further examination of the association with working memory.

In sum, while there is need for further validation of the AIHQ and Epps in a larger sample, there are currently no other validated assessments to measure attributions in persons with TBI. The findings suggest both measures have adequate construct and predictive validity. Although the AIHQ and Epps measures are still experimental, these findings provide initial support for their use in TBI research and suggest they may also have some clinical utility for evaluating negative attributions in patients with TBI.

In deciding on which measure to use and/or whether to administer the full set of scenarios or ambiguous-only, the following summary of findings may assist (also see Table 5). The Epps measure appears to have significantly better construct validity and better predictive validity (good vs sufficient) and sensitivity for trait aggression. Although statistical comparisons did not support Epps as having superior predictive validity compared to AIHQ, this may have been a result of the sample size. In terms of practicality, reading ease and grade level seem to be acceptable for both measures. The main difference and disadvantage for the Epps, is the time it takes to administer. That said, there is rationale to use ambiguous-only items, for both measures, which could be a substantial time saver. For the most part, construct and predictive validity were 
not compromised when only data from the ambiguous scenarios were used. For instance, in the case of the AIHQ, attribution-anger associations were always more robust for ambiguous-only items. For the Epps scenarios, the attribution-anger associations remained strong regardless of whether the full set of scenarios or the ambiguous-only scenarios were used. Although the predictive validity for the Epps blame attributions received a lower classification (sufficient) for the ambiguous-only scenarios, it was borderline (.68) to the .7 criteria for a "good" classification. Finally, the AIHQ has two open-ended items which must be scored (hostility attributions and anticipated aggressive behavioral responses), which requires one to learn how to score these items. The open-ended aggression question was not discussed in the manuscript because it did not have a comparative item on the Epps, but is worth noting in this summary, as some may see it as an advantage. Although, scoring these items may add additional time and burden, qualitatively, this information could be quite informative.

\section{<Insert Table 5 here $>$}

\section{Clinical applicability}

There is currently no standardized clinical measure available to assess negative attribution bias in persons with any type of brain injury, including TBI. Assessment of this information can be important because it can help to explain social difficulties that someone with TBI may be having that may prevent them from successfully integrating into their social groups and communities. While neither the AIHQ or the Epps measures yet meet the level of a standardized assessment similar to other measures used as part of clinical assessment, they may be used as a supplement to help clinicians understand clients' perceptions of social interactions that may be influencing behavior. The cut-off scores presented in this manuscript, while not meant to serve as normative data, can provide clinicians with a certain level of confidence 
regarding the likelihood of a client reacting with anger or aggression to perceived negative intent in others. This can inform treatment recommendations, such as training in emotional regulation, self-monitoring for triggers of anger, and perspective training aimed at helping them to more realistically interpret others' intent. Future studies could develop normative data for these measures that could then be used more formally in assessments.

\section{Limitations}

A few limitations should be considered. It should be noted that construct validity was calculated from items within the same measure (relations between attribution and anger responses to the scenarios), which could have inflated the correlation coefficients. However, this approach was necessary for determining how well these measures supported the attributionemotion theory. The small sample size at two centers may not be representative of the broader population of persons with TBI. The sample was limited to persons with complicated mild to severe TBI and may not be generalizable to those with uncomplicated mild TBI or blast-related TBI. Cultural considerations were not addressed in this primarily White sample in which most had a high school education or higher. Utility of these measures in minority groups and those with lower education should be investigated in future studies. It should also be noted that aggression was self-evaluated. Since poor insight can be a problem for some individuals with TBI, future studies should consider consider aggression ratings from family or friends. The cutoff scores do not represent normative data and should not be interpreted as such. Criterion validation for cut-off scores will be an important next step. Also, age, education, and preferably race/ethnicity- corrected normative data for the AIHQ and Epps scenarios should be developed before they are adopted widely as part of clinical assessment.

\section{CONCLUSION}


The AIHQ and Epps scenarios are promising tools that may supplement more standardized clinical evaluations, providing information on how clients perceive others' actions and the likelihood that their perceptions may be associated with anger or aggression. Cut-off scores may have utility for targeting specific treatments to increase self-monitoring of perceptions, adopting different perspectives, and regulating emotional and behavioral reactions.

\section{REFERENCES}

1. Neumann D, Malec JF, Hammond FM. The Relations of Self-Reported Aggression to Alexithymia, Depression, and Anxiety After Traumatic Brain Injury. The Journal of Head Trauma Rehabilitation. 2016 doi: 10.1097/HTR.0000000000000261.

2. Neumann D, Malec JF, Hammond FM. The association of negative attributions with irritation and anger after brain injury. Rehabilitation psychology. 2015;60(2):155. 
3. Neumann D, Malec JF, Hammond FM. Negative Attribution Bias and Anger After Traumatic Brain Injury. Journal of Head Trauma Rehabilitation. 2017;10.1097/HTR.0000000000000259(32(3) ):197-204

4. Ellsworth PC, Scherer KR. Appraisal processes in emotion. Handbook of affective sciences. 2003:572-595.

5. Epps J, Kendall PC. Hostile attributional bias in adults. Cognitive Therapy and Research. 1995;19(2):159-178.

6. Gross JJaT, R.A. In: Gross JJ, ed. Handbook of Emotion Regulation. New York: Guilford Press; 2007:1-10.

7. Bailey CA, Ostrov JM. Differentiating forms and functions of aggression in emerging adults: Associations with hostile attribution biases and normative beliefs. Journal of Youth and Adolescence. 2008;37(6):713-722.

8. Combs DR, Penn DL, Wicher M, Waldheter E. The Ambiguous Intentions Hostility Questionnaire (AIHQ): a new measure for evaluating hostile social-cognitive biases in paranoia. Cognitive neuropsychiatry. 2007;12(2):128-143.

9. An SK, Kang JI, Park JY, Kim KR, Lee SY, Lee E. Attribution bias in ultra-high risk for psychosis and first-episode schizophrenia. Schizophrenia research. 2010;118(1):54-61.

10. Steinberg MS, Dodge KA. Attributional bias in aggressive adolescent boys and girls. Journal of Social and Clinical Psychology. 1983;1(4):312-321.

11. Neumann D, Sander AM, Perkins SM, et al. Assessing Negative Attributions After Brain Injury With the Ambiguous Intentions Hostility Questionnaire. Journal of Head Trauma Rehabilitation. 2020.

12. Witwer N, Dyar D, Perkins S, Hammond F, Sander A, Neumann D. Assessing Negative Attributions and Anger After Brain Injury: A Comparison of Measures. Archives of Physical Medicine and Rehabilitation. 2019;100(10):e44-e45.

13. Pinkham AE, Penn DL, Green MF, Buck B, Healey K, Harvey PD. The social cognition psychometric evaluation study: results of the expert survey and RAND panel. Schizophrenia bulletin. 2013;40(4):813-823.

14. Buck B, Iwanski C, Healey KM, et al. Improving measurement of attributional style in schizophrenia; A psychometric evaluation of the Ambiguous Intentions Hostility Questionnaire (AIHQ). Journal of psychiatric research. 2017;89:48-54.

15. Combs DR, Penn DL, Michael CO, et al. Perceptions of hostility by persons with and without persecutory delusions. Cognitive neuropsychiatry. 2009;14(1):30-52.

16. Buss AH, Perry M. The aggression questionnaire. Journal of Personality and Social Psychology. 1992;63(3):452-459.

17. Dyer KFW, Bell R, McCann J, Rauch R. Aggression after traumatic brain injury: Analysing socially desirable responses and the nature of aggressive traits. Brain Injury. 2006;20(11):1163-1173.

18. Greve KW, Sherwin E, Stanford MS, Mathias C, Love J, Ramzinski P. Personality and neurocognitive correlates of impulsive aggression in long-term survivors of severe traumatic brain injury. Brain Injury. 2001;15(3):255-262.

19. Holtzworth-Munroe A, Rehman U, Herron K. General and spouse-specific anger and hostility in subtypes of maritally violent men and nonviolent men*. Behavior Therapy. 2000;31(4):603-630.

20. Hoptman MJ, D'Angelo D, Catalano D, et al. Amygdalofrontal functional disconnectivity and aggression in schizophrenia. Schizophrenia Bulletin. 2009.

21. Palmer EJ, Thakordas V. Relationship between bullying and scores on the Buss-Perry Aggression Questionnaire among imprisoned male offenders. Aggressive Behavior. 2005;31(1):56-66.

22. Evans JD. Straightforward statistics for the behavioral sciences. Thomson Brooks/Cole Publishing Co; 1996. 
23. Steiger JH. Tests for comparing elements of a correlation matrix. Psychological bulletin. 1980;87(2):245.

24. Pepe MS. The statistical evaluation of medical tests for classification and prediction. Medicine; 2003.

25. Šimundić A-M. Measures of diagnostic accuracy: basic definitions. Ejifcc. 2009;19(4):203.

26. DeLong ER, DeLong DM, Clarke-Pearson DL. Comparing the areas under two or more correlated receiver operating characteristic curves: a nonparametric approach. Biometrics. 1988:837-845.

27. Youden WJ. Index for rating diagnostic tests. Cancer. 1950;3(1):32-35. 
Table 1: Demographics and Injury Information

\begin{tabular}{|c|c|}
\hline Variables & $N=85$ \\
\hline Age [Mean (SD)] & $40.0(13.3)$ \\
\hline Education level [Mean (SD)] & $14.1(2.1)$ \\
\hline Gender, $\mathrm{n}(\%)$ Male & $47(55.3 \%)$ \\
\hline \multicolumn{2}{|l|}{ Race, n (\%) } \\
\hline White & $64(75.3 \%)$ \\
\hline Black & $17(20 \%)$ \\
\hline Other & $4(4.7 \%)$ \\
\hline $\begin{array}{l}\text { Time since injury }[\text { Mean }(\mathrm{SD})] \\
\text { years }\end{array}$ & $8.5(9.4)$ \\
\hline \multicolumn{2}{|l|}{ Cause of injury, $n(\%)$} \\
\hline Vehicular & $36(42.4 \%)$ \\
\hline Fall & $17(20.0 \%)$ \\
\hline Assault & $8(9.4 \%)$ \\
\hline Other & $24(28.2 \%)$ \\
\hline \multicolumn{2}{|l|}{ Post-traumatic amnesia, n (\%) } \\
\hline$<1 \mathrm{hr}$ & $6(7.4 \%)$ \\
\hline$>1 \mathrm{hr}$, but $<24 \mathrm{hrs}$ & $4(5.0 \%)$ \\
\hline $1-6$ days & $11(13.6 \%)$ \\
\hline 7-29 days & $28(34.6 \%)$ \\
\hline$\geq 30$ days & $32(39.5 \%)$ \\
\hline Missing & 4 \\
\hline \multicolumn{2}{|l|}{ Loss of consciousness, $n(\%)$} \\
\hline$<30$ mins & $25(32.9 \%)$ \\
\hline$>30$ mins, but $<24 \mathrm{hrs}$ & $16(21.1 \%)$ \\
\hline 1-6 days & $13(17.1 \%)$ \\
\hline 7-29 days & $13(17.1 \%)$ \\
\hline
\end{tabular}


$\geq 30$ days

$9(11.8 \%)$

Missing 
Table 2. Construct Validity. Estimated Spearman's rank correlation coefficient $\hat{\rho}_{S}$ between attribution scores and anger response for AlHQ and Epps, under all scenarios combined and under only the ambiguous scenario. The P-values are results from comparing the construct validity of the two measures' (i.e., differences in the strength of their attributionanger relationships).

\begin{tabular}{|c|c|c|c|c|}
\hline & Attribution & $\begin{array}{c}\text { AIHQ } \\
\widehat{\rho}_{s}(95 \% \mathrm{Cl})\end{array}$ & $\begin{array}{c}\text { EPPS } \\
\widehat{\rho}_{s}(95 \% \mathrm{Cl})\end{array}$ & P-value \\
\hline \multirow{3}{*}{$\begin{array}{c}\text { All scenarios } \\
\text { combined }\end{array}$} & Intent & $\begin{array}{c}0.50 \\
(0.33-0.65)\end{array}$ & $\begin{array}{c}0.72 \\
(0.62-0.80)\end{array}$ & $<0.001$ \\
\hline & Hostility & $\begin{array}{c}0.39 \\
(0.19-0.55)\end{array}$ & $\begin{array}{c}0.74 \\
(0.64-0.82)\end{array}$ & $<0.001$ \\
\hline & Blame & $\begin{array}{c}0.65 \\
(0.50-0.76)\end{array}$ & $\begin{array}{c}0.70 \\
(0.59-0.79)\end{array}$ & $<0.001$ \\
\hline \multirow{3}{*}{$\begin{array}{l}\text { Ambiguous } \\
\text { scenarios }\end{array}$} & Intent & $\begin{array}{c}0.57 \\
(0.41-0.70)\end{array}$ & $\begin{array}{c}0.63 \\
(0.49-0.75)\end{array}$ & $<0.001$ \\
\hline & Hostility & $\begin{array}{c}0.49 \\
(0.30-0.63)\end{array}$ & $\begin{array}{c}0.74 \\
(0.62-0.82)\end{array}$ & $<0.001$ \\
\hline & Blame & $\begin{array}{c}0.71 \\
(0.59-0.80)\end{array}$ & $\begin{array}{c}0.61 \\
(0.46-0.73)\end{array}$ & $<0.001$ \\
\hline
\end{tabular}

Table 3. Predictive validity: Areas under the ROC curve (AUCs) ${ }^{1}$ for AIHQ and Epps negative attribution scores as well as the sensitivity and specificity at the optimal cutoff point for detecting higher-than-average aggression traits on Buss Perry AQ (total score $\geq 56$ ).

\begin{tabular}{|l|l|c|c|c|c|c|}
\hline & Attribution Score & AUC (SE) & 95\% Cl & $\begin{array}{c}\text { Diff AUC } \\
\text { (P-value }^{2} \text { ) }\end{array}$ & $\begin{array}{c}\text { Cutoff } \\
\text { point }\end{array}$ & Sen / Spe \\
\hline \multirow{2}{*}{$\begin{array}{l}\text { All } \\
\text { scenarios } \\
\text { combined }\end{array}$} & AlHQ intent & $0.672(0.059)$ & $0.556-0.788$ & 0.087 & 3.5 & $0.646 / 0.703$ \\
& Epps intent & $0.759(0.055)$ & $0.651-0.867$ & $(0.093)$ & 4.9 & $0.750 / 0.757$ \\
\cline { 2 - 7 } & AlHQ hostility & $0.662(0.061)$ & $0.544-0.781$ & 0.053 & 1.8 & $0.546 / 0.730$ \\
& Epps hostility & $0.716(0.058)$ & $0.602-0.830$ & $(0.457)$ & 4.2 & $0.729 / 0.676$ \\
\hline
\end{tabular}




\begin{tabular}{|c|c|c|c|c|c|c|}
\hline & $\begin{array}{l}\text { AlHQ blame } \\
\text { Epps blame }\end{array}$ & $\begin{array}{l}0.640(0.061) \\
0.711(0.057)\end{array}$ & $\begin{array}{l}0.520-0.760 \\
0.599-0.823\end{array}$ & $\begin{array}{c}0.071 \\
(0.170)\end{array}$ & $\begin{array}{l}3.1 \\
5.7\end{array}$ & $\begin{array}{l}0.708 / 0.649 \\
0.750 / 0.622\end{array}$ \\
\hline & $\begin{array}{l}\text { AlHQ composite } \\
\text { Epps composite }^{4}\end{array}$ & $\begin{array}{l}0.686(0.059) \\
0.770(0.053)\end{array}$ & $\begin{array}{c}0.570-0.802 \\
0.666-0.874\end{array}$ & $\begin{array}{c}0.084 \\
(0.161)\end{array}$ & $\begin{array}{l}0.3 \\
-0.2\end{array}$ & $\begin{array}{l}0.625 / 0.784 \\
0.875 / 0.622\end{array}$ \\
\hline \multirow{4}{*}{$\begin{array}{l}\text { Ambiguous } \\
\text { scenarios }\end{array}$} & $\begin{array}{l}\text { AlHQ intent } \\
\text { Epps intent }\end{array}$ & $\begin{array}{l}0.635(0.061) \\
0.714(0.057)\end{array}$ & $\begin{array}{l}0.515-0.754 \\
0.603-0.826\end{array}$ & $\begin{array}{c}0.080 \\
(0.173)\end{array}$ & $\begin{array}{l}3.6 \\
5.0\end{array}$ & $\begin{array}{l}0.500 / 0.811 \\
0.688 / 0.676\end{array}$ \\
\hline & $\begin{array}{l}\text { AIHQ hostility } \\
\text { Epps hostility }\end{array}$ & $\begin{array}{l}0.603(0.062) \\
0.732(0.057)\end{array}$ & $\begin{array}{l}0.481-0.725 \\
0.621-0.843\end{array}$ & $\begin{array}{c}0.129 \\
(0.065)\end{array}$ & $\begin{array}{l}1.8 \\
4.4\end{array}$ & $\begin{array}{l}0.646 / 0.622 \\
0.708 / 0.730\end{array}$ \\
\hline & $\begin{array}{l}\text { AlHQ blame } \\
\text { Epps blame }\end{array}$ & $\begin{array}{l}0.628(0.062) \\
0.680(0.060)\end{array}$ & $\begin{array}{l}0.508-0.749 \\
0.562-0.798\end{array}$ & $\begin{array}{l}0.0518 \\
(0.370)\end{array}$ & $\begin{array}{l}3.0 \\
4.6\end{array}$ & $\begin{array}{l}0.604 / 0.649 \\
0.917 / 0.432\end{array}$ \\
\hline & $\begin{array}{l}\text { AlHQ composite }^{5} \\
\text { Epps composite }^{6}\end{array}$ & $\begin{array}{l}0.638(0.061) \\
0.738(0.057)\end{array}$ & $\begin{array}{l}0.519-0.757 \\
0.627-0.849\end{array}$ & $\begin{array}{c}0.100 \\
(0.081)\end{array}$ & $\begin{array}{l}0.3 \\
0.1\end{array}$ & $\begin{array}{l}0.583 / 0.730 \\
0.792 / 0.649\end{array}$ \\
\hline
\end{tabular}

Abbreviations: $\mathrm{SE}=$ standard error; $\mathrm{Cl}=$ confidence interval; Sen=sensitivity; Spe=specificity.

${ }^{1} \mathrm{AUC}$ were obtained under the convention that a score above the cutoff point indicates higher-than-average trait aggression. ${ }^{2} \mathrm{P}$ value from a nonparametric test that compares AUC values between AIHQ and Epps attribution scales.

${ }^{3} \mathrm{AlHQ}$ total composite $=\mathbf{- 3 . 7 6 2}+(\mathbf{0 . 2 4 9}$ avg aihq total intent $)+(\mathbf{1 . 3 8 0}$ aihq avg total hostility $)+(\mathbf{0 . 2 2 8} *$ aihq avg total blame $)$. ${ }^{4}$ EPPS total composite $=\mathbf{- 3 . 7 2 4}+(0.996 *$ epps total intent $)-(0.293 *$ epps total hostility $)+(\mathbf{0 . 0 6 6} *$ epps total blame $)$.

${ }^{5} \mathrm{AlHQ}$ ambiguous composite $=\mathbf{- 1 . 2 1 8}+(\mathbf{0 . 2 5 2} *$ aihq total intent $)+(\mathbf{1 . 1 5 0} *$ aihq total hostility $)+(\mathbf{0 . 1 3 2} *$ aihq total blame $)$. ${ }^{6}$ EPPS ambiguous composite $=\mathbf{- 2 . 7 2 3}+(\mathbf{0 . 2 6 8} *$ epps total intent $)+(\mathbf{0 . 2 9 4} *$ epps total hostility $)+(\mathbf{0 . 0 6 4} *$ epps total blame $)$. 


\begin{tabular}{|c|c|c|}
\hline & AIHQ & Epps \\
\hline Number of Scenarios & $\begin{array}{l}15 \text { Total } \\
5 \text { Ambiguous }\end{array}$ & $\begin{array}{l}21 \text { Total } \\
7 \text { Ambiguous }\end{array}$ \\
\hline $\begin{array}{l}\text { Time to Administer Full Measure } \\
\text { (min:sec) }\end{array}$ & $\begin{array}{l}\text { Median: 17:48 } \\
\text { Min: 14:36 } \\
\text { Max: 23:28 }\end{array}$ & $\begin{array}{l}\text { Median: 29:04 } \\
\text { Min: 23:58 } \\
\text { Max: 37:02 }\end{array}$ \\
\hline Number of words per scenario & $\begin{array}{l}\text { Median: } 23 \\
\text { Min: } 12 \\
\text { Max: } 43\end{array}$ & $\begin{array}{l}\text { Median: } 104 \\
\text { Min: } 50 \\
\text { Max: } 128\end{array}$ \\
\hline Reading Ease & $\begin{array}{l}\text { Median: } 87.4 \\
\text { Min: } 62.1 \\
\text { Max: } 96\end{array}$ & $\begin{array}{l}\text { Median: } 77.2 \\
\text { Min: } 56.8 \\
\text { Max: } 86.9\end{array}$ \\
\hline Flesch-Kincaid Reading Grade Level & $\begin{array}{l}\text { Median: } 4.9 \\
\text { Min: } 3 \\
\text { Max: } 10.3\end{array}$ & $\begin{array}{l}\text { Median: } 6 \\
\text { Min: } 4.3 \\
\text { Max: } 8.6\end{array}$ \\
\hline
\end{tabular}




\begin{tabular}{|c|c|c|}
\hline & AIHQ & Epps \\
\hline Construct Validity & $\begin{array}{l}\text { Associations are mostly } \\
\text { moderate, with exception of } \\
\text { Blame-anger, which was strong, } \\
\text { and hostility-anger was weak for } \\
\text { full set of scenarios. }\end{array}$ & Associations all strong \\
\hline $\begin{array}{l}\text { Predictive for trait } \\
\text { aggression and } \\
\text { sensitivity }\end{array}$ & Sufficient for all & $\begin{array}{l}\text { Good for all, except Ambiguous } \\
\text { Blame, which was sufficient } \\
\text { More sensitive at correctly } \\
\text { identifying someone who truly has } \\
\text { above average aggression. }\end{array}$ \\
\hline Readability & "Easy"; $5^{\text {th }}$ grade reading level & $\begin{array}{l}\text { "Fairly Easy"; } 6^{\text {th }} \text { grade reading } \\
\text { level }\end{array}$ \\
\hline Administration time & Typically, 18 min & Typically, $30 \mathrm{~min}$ \\
\hline Scoring demands & $\begin{array}{l}2 \text { open-ended items (hostility and } \\
\text { aggressive behavioral response) } \\
\text { which require raters to rate } \\
\text { responses }\end{array}$ & $\begin{array}{l}\text { All items self-rated; does not } \\
\text { evaluate potentially aggressive } \\
\text { behavioral responses. }\end{array}$ \\
\hline $\begin{array}{l}\text { Support ambiguous- } \\
\text { only scenarios }\end{array}$ & Yes, validity remained the same. & Yes, validity remained the same. \\
\hline
\end{tabular}

